\title{
洱海四种沉水植物对弱光环境的适应性比较”
}

\author{
张忠海 ${ }^{1,3}$,杨 桐 ${ }^{2}$,王 昊 $^{3}$, 张霄林 $^{3}$, 曹 特 $^{3}$, 倪乐意 ${ }^{3}$, 袁昌波 $^{3 * *}$ \\ (1: 大连海洋大学, 大连 116023) \\ (2: 大理市洱海管理局,大理 671000) \\ (3: 中国科学院水生生物研究所,武汉 430072)
}

\begin{abstract}
摘 要: 水下弱光环境是水生态系统沉水植被恢复面临的常见问题, 因此研究沉水植物在弱光胁迫下的适应性是必要 的. 本研究以云南大理州洱海南部重度退化的湖区 (惯称湖心平台, 曾分布有大面积沉水植物) 作为实验地点, 选取 4 种 沉水植物一一苦草 (Vallisneria natans)、轮叶黑藻 (Hydrilla verticillata)、穗花狐尾藻 (Myriophyllum spicatum)、竹叶眼子菜 (Potamogeton wrightii) 作为研究对象, 开展原位盆栽实验, 通过比较 4 种沉水植物的生长情况来选取潜在的目标物种, 为 洱海湖心平台沉水植被恢复提供科学依据. 结果表明: 1) 水下弱光环境对 4 种沉水植物生长均造成胁迫,生物量和株高 显著性降低,物种间的相对生物量差异表现为: 苦草和竹叶眼子菜 > 轮叶黑藻和穗花狐尾藻, 相对株高差异表现为: 苦 草 $>$ 竹叶眼子菜 > 穗花狐尾藻 > 轮叶黑藻; 2) 生理特征方面, 苦草、穗花狐尾藻和竹叶眼子菜有相似的胁迫反应, 均表 现为: 氮 $(\mathrm{N})$ 和游离氨基酸含量均升高, 碳氮比 $(\mathrm{C}: \mathrm{N}$ 比)、可溶性糖含量与淀粉含量均下降, 仅苦草的叶绿素含量升高, 而轮叶黑藻的生理胁迫反应表现为:氨基酸含量下降,可溶性糖和淀粉含量升高; 3 ) 四者最终存活率为: 苦草 > 竹叶眼子 菜 > 穗花狐尾藻 > 轮叶黑藻, 且苦草相对生物量和相对株高高于其他 3 种植物. 以上原位实验结果表明, 与其他 3 种植 物相比,苦草更能适应湖心平台的水下弱光环境,可考虑作为湖心平台沉水植被恢复的目标物种.
\end{abstract}

关键词: 水生植被恢复; 弱光适应;沉水植物;洱海

\section{Comparative study on the adaptability of four submerged macrophytes to low light envi- ronment in Lake Erhai *}

\author{
Zhang Zhonghai ${ }^{1,3}$, Yang Tong ${ }^{2}$, Wang $\mathrm{Hao}^{3}$, Zhang Xiaolin ${ }^{3}, \mathrm{Cao} \mathrm{Te}^{3}$, Ni Leyi ${ }^{3}$ \& Yuan Changbo ${ }^{3 * *}$ \\ (1: Dalian Ocean University, Dalian 116023, P.R.China) \\ (2:Dali Erhai Administration, Dali 671000, P.R.China) \\ (3: Institute of Hydrobiology, Chinese Academy of Sciences, Wuhan 430072, P.R. China)
}

Abstract: Low light environment under water is a common problem in the revegetation of submerged macrophytes. Therefore, it is necessary to study their adaptability to low light stress. The central part of the southern Lake Erhai (a mesotrophic lake in Yunnan Province, China) is flat, with an average annual water depth of about $6.3 \mathrm{~m}$, which was called the “lake center platform” (LCP) . Large areas of aquatic vegetation were once existed in the LCP, which had important roles in the lake ecological function but completely disappeared since 2003. Therefore, we chose the LCP as our experimental site, and select four common submerged macrophytes (Vallisneria natans, Hydrilla verticillata, Myriophyllum spicatum, and Potamogeton wrightii) as the research objects for the in-situ pot experiment, then select the potential species for revegetation by comparing their growth and final survival rates. Our results showed that: 1) the growth of the four species was stressed under the low light environment, and the biomass and plant height significantly reduced. The relative differences in biomass among species were as follows: V. natans and P. wrightii $>$ M. spicatum and $H$. verticillata, and the relative differences in plant height were as follows: V. natans $>$ P. wrightii $>$ M. spicatum $>$ H. verticillate; 2) In terms of physiological characteristics, V. natans, P. wrightii and $M$. spicatum had similar physiological response to low light stress-the contents of $\mathrm{N}$ and free amino acids increased, the ratio of $\mathrm{C}: \mathrm{N}$, soluble carbohydrate and starch content decreased.

* 2020-09-05 收稿; 2020-10-19 收修改稿.

国家自然科学基金项目 (31870446) 和淡水生态与生物技术国家重点实验室项目 (2019FBZ01) 联合资助.

** 通信作者; E-mail: yuancb@ihb.ac.cn. 
Only the chlorophyll content of $V$. natans increased. The physiological response of $H$. verticillata to low light stress was as follows: the content of free amino acids decreased, and those of soluble carbohydrate and starch increased; 3 ) the final survival rates of four species were as follows: V. natans $>$ P. wrightii $>M$. spicatum $>H$. verticillata. In summary, the relative biomass and plant height and final survial rate of $V$. natans were highest, therefore it was more suitable for underwater low light environment and could be considered as a pioneer species for revegetation in LCP.

Keywords: Revegetation of aquatic vegetation; low light; submerged macrophyte; Lake Erhai

近年来, 随着经济加速发展和资源利用剧增, 人类对湖泊开发过度, 湖泊内营养源富集, 导致湖泊生态 系统退化, 蓝藻水华大量暴发, 水体透明度不断下降, 沉水植被退化 ${ }^{[1]}$. 沉水植物是水生生态系统的生产者, 其兴衰对湖泊生态系统的结构和功能有重要影响 ${ }^{[2]}$. 沉水植物通过提高湖泊的空间异质性, 抑制生物性和 非生物性悬浮物的生成; 提高水体溶解氧浓度; 降低水体氮磷营养盐浓度, 抑制藻类生长, 改善水下光照条 件; 为上游食物链中的各类生物类群提供了食物来源、栖息地和其他必需条件 ${ }^{[3-5]}$; 沉水植被的各项直接和 间接的生态作用促进了湖泊维持清水稳态 ${ }^{[6]}$. 因此, 在湖泊修复过程中水生植被恢复具有重要意义.

在污染严重的水体中, 沉水植物难以自然恢复, 湖泊水柱中极低的透明度及植物繁殖体的缺乏是限制 水生植被恢复的主要因素 ${ }^{[7-8]}$. 在这种情况下, 对于植被严重退化的湖泊应尽快采用有效的生态措施, 积极 开展水生植被恢复与重建工作 ${ }^{[9]}$. 世界各地对于湖泊沉水植被恢复做了许多尝试,但少有大空间尺度上沉 水植被恢复成功的先例, 其中一个重要的原因就是过于注重植物本身而忽视了其生长所需的环境条件 ${ }^{[10]}$. 水生植物生长受到多种因素的影响, 如光照、温度、水质、底质和生物因素等. 一般认为光照强度是影响沉水 植物生长的主要限制因子 ${ }^{[11]}$, 王韶华等研究后海沉水植物发现: 透明度过低引起的光照不足是后海沉水植 物死亡的主要原因 ${ }^{[12]}$; 符辉的研究发现: 近 30 年来, 洱海水质 (透明度)下降对沉水植物造成严重的弱光胁 迫, 导致沉水植被退化 ${ }^{[13]}$. 因此, 研究沉水植物对弱光胁迫的适应能力对于沉水植被恢复十分必要. 一般认 为环境光强持久或短时间显著低于植物光饱和点的光环境, 可以称为弱光逆境 ${ }^{[14]}$. 此条件下, 沉水植物的 光合作用受到强烈影响, 生长严重受抑 ${ }^{[15]}$, 生理上也会受到损伤 ${ }^{[16]}$. 当前, 对于弱光胁迫下沉水植物的响应 多采用室内控制实验进行研究, 这导致实践时往往难以起到很好的效果, 本研究选择洱海水生植被重度退 化区域进行原位实验,对水生植被的恢复可以起到良好的指导作用.

洱海位于云南大理州境内, 属于高原淡水湖泊. 洱海南部有一部分湖区 $\left(25.64375^{\circ} \sim 25.71297^{\circ} \mathrm{N}\right.$, $100.21799^{\circ} \sim 100.24011^{\circ} \mathrm{E}$ ) 湖底高程较高, 形成一处高于四周区域的“平台” ( 以下称“湖心平台”). 1998 年 之前, 湖心平台尚有大片沉水植被分布, 是洱海沉水植物成片连续分布的最大区域. 1981-1983 年, 湖心平 台水域水生植被分布面积达到 $23 \mathrm{~km}^{2}$, 占全湖水生植被面积的 $29.76 \%{ }^{[17]} ; 1984-1994$ 年,洱海受富营养化 影响而水质变差,并在 1996 年发生第一次水华, 对沉水植被造成了极大的破坏, 1997 年实施了 “双取消”工 程 (取消网箱养鱼和机动船只) 后, 沉水植被大量恢复, 其分布面积和生物量显著增加 ${ }^{[18-19]}$; 至 1998 年湖心 平台区域水生植被分布面积达到 $33.41 \mathrm{~km}^{2}$, 占全湖水生植被面积的 $34.80 \%$, 而后 2003 年洱海再次暴发水 华, 此后 2 年多的时间里湖心平台植被逐渐消失殆尽 ${ }^{[13]}$ (表 1 ). 因此, 若能在此大面积退化区域恢复水生植 被,将显著增加洱海水生植被面积,对洱海生态功能的修复具有重要意义.

表 1 洱海南部湖心平台水域水生植被变化 1 17-18,20-21]

Tab.1 Changes of aquatic vegetation in the platform waters of southern Lake Erhai ${ }^{[17-18,20-21]}$

\begin{tabular}{cccc}
\hline 时间 & 分布面积 $/ \mathrm{km}^{2}$ & 占全湖分布的比例 & 主要物种 \\
\hline $1975-1983$ 年 & - & - & 金鱼藻、苦草、轮叶黑藻 \\
$1981-1983$ 年 & 23.00 & $29.76 \%$ & 金鱼藻、微齿眼子菜 \\
1998 年 & 33.41 & $34.80 \%$ & 微齿眼子菜、苦草、轮叶黑藻 \\
2009 年 & 0 & 0 & 没有水生植物 \\
\hline
\end{tabular}

2015 年以来, 随着洱海环保力度加大, 洱海水质逐年变好, 透明度逐年提高, 水质得到改善, 理论上湖心 平台有沉水植物恢复的可能性, 但是一直没有出现沉水植被的自然恢复, 因此我们希望通过人工强化的修 
复措施实现该区域的沉水植被重建. 本研究的核心问题是, 洱海哪种常见本土沉水植物可以在湖心平台存 活并形成稳定群落? 根据湖心平台区域水生植被消失之前的优势物种和湖心平台的环境特征, 选择 4 种可 能适应该区域的沉水植物: 苦草 (Vallisneria natans)、轮叶黑藻 (Hydrilla verticillata)、穗花狐尾藻 (Myriophyllum spicatum) 、竹叶眼子菜 (Potamogeton wrightii), 其中苦草和轮叶黑藻是湖心平台的历史优势 种, 两者耐污能力强, 有较强的净化能力; 穗花狐尾藻耐污能力强, 净化效果好, 繁殖快, 再生能力强, 竹叶眼 子菜地下茎发达, 对水质具有较强的适应能力, 4 种植物是沉水植被恢复中经常被选择的物种 ${ }^{[22]}$, 具有在湖 心平台恢复的可能性, 并且在洱海容易获取. 根据这 4 种沉水植物的原位生长状况, 比较四者的适应能力, 来篮选哪些植物最适合作为退化区植被恢复的物种.

\section{1 材料与方法}

\section{1 实验材料}

实验用的 4 种沉水植物均来自洱海水生植物种苗繁育基地, 基地培养的沉水植物种源均源于洱海湖区. 同一种植物选用的是生长茂盛、健康和生长指标大体一致的植株, 4 种植物株高保持大体一致 $(70 \sim 90 \mathrm{~cm})$.

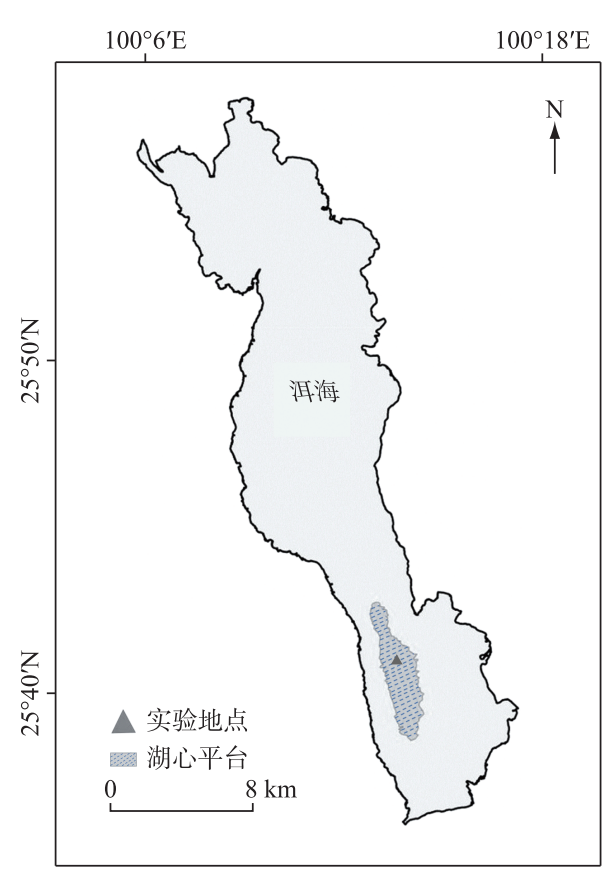

图 1 实验区域示意图

Fig.1 Schematic diagram of experimental area

\section{2 实验时间}

实验时间选择沉水植物在洱海的生长旺盛的时期, 从 2018 年 6 月 7 日 -8 月 7 日,共 9 周 $(63 \mathrm{~d})$.

\section{3 实验地点}

实验地点选择在湖心平台中心区域 $\left(25.684234^{\circ} \mathrm{N}\right.$, $100.226728^{\circ} \mathrm{E}$ ) ( 图 1).

\section{4 实验设计}

将 4 种沉水植物作为 4 个实验组, 通过测定生物量、株 高以及叶绿素、 $\mathrm{C} 、 \mathrm{~N}$ 、游离氨基酸、可溶性糖、淀粉含量, 比 较其在原位生长的适应性.

本研究采用沉桶盆栽的方式开展. 种植桶是白色塑料 桶 (上直径 $35 \mathrm{~cm}$, 高 $33 \mathrm{~cm}$, 底直径 $27 \mathrm{~cm}$ ), 在桶内填充底 质(湖心平台底部淤泥) $15 \mathrm{~cm}$, 按照每桶 30 株的密度将相 应植株均匀植于桶内, 每个实验组设置 20 个平行 (桶). 种 植桶沉人水底前, 用另一端绑着浮标 (直径 $10 \mathrm{~cm}$ 的白色泡 沫球) 的绳子系在桶上, 绳长度 $7.5 \mathrm{~m}$, 略大于实验地点的 水深, 保证种植桶不受浮标飘动影响, 然后缓慢沉人实验 区域.

\section{5 测量指标}

1.5.1 水环境指标实验期间, 每周测量一次实验区域的光 合有效辐射、水温、 $\mathrm{pH}$ 、透明度、实验区水体总氮 $(\mathrm{TN})$ 、氨氮 $\left(\mathrm{NH}_{3}-\mathrm{N}\right)$ 、硝态氮 $\left(\mathrm{NO}_{3}^{-}-\mathrm{N}\right)$ 、总磷 $(\mathrm{TP})$ 、正磷酸盐 $\left(\mathrm{PO}_{4}^{3-}-\mathrm{P}\right)$

浓度. 水温 $\mathrm{pH}$ 用多参数水质分析仪 YSI ( Yellow Springs Instruments, Ohio, US ) 测量, 透明度用透明度盘在顺 光处测量, 水底光合有效辐射使用水下照度计 ( Li-1400; Li-Cor Company, Lincoln, NE, U.S.A; UWQ-8342) 于上 午 11:00-12:00 之间在湖心底部测定, 水体 $\mathrm{TN} 、 \mathrm{NH}_{3}-\mathrm{N} 、 \mathrm{NO}_{3}^{-}-\mathrm{N} 、 \mathrm{TP} 、 \mathrm{PO}_{4}^{3-}-\mathrm{P}$ 浓度根据标准方法测定 ${ }^{[23]}$.

1.5.2 沉水植物生长和生理指标在实验前每种植物取 5 株样本, 测量株高和生物量, 以其平均值作为初始 株高和初始生物量. 实验周期内, 各物种按照 5 桶为单位进行循环监测, 每周统计 5 桶中数植株数量作为存 活量, 并分别从每桶随机取 1 株植株带回实验室, 测量植株株高 (相对株高=测量株高/初始株高), 取植株 从上到下第 3 片叶片来测量叶绿素含量, 叶绿素含量通过丙酮一乙醇提取法测定 ${ }^{[24]}$, 之后经 $80^{\circ} \mathrm{C}$ 烘干至恒 重后以测量生物量 (相对生物量 =测量生物量/初始生物量), 将 5 株植物干样合并进行研磨成粉末并经 200 目笁过滤后, 测定游离氨基酸、可溶性糖、淀粉、碳、氮含量. 植物组织碳、氮含量通过元素分析仪 (Flash EA 
1112 , CE Instruments, Italy) 测定; 将 $50 \mathrm{mg}$ 烘干的植物组织用 $80 \%$ 乙醇在 $80^{\circ} \mathrm{C}$ 的水浴萃取 $20 \mathrm{~min}$,重复 2 次, 离心后合并上清液, 并定溶到 $5 \mathrm{~mL}$ 用于测定可溶性糖和游离氨基酸的含量, 萃取后的残渣中加人 $2 \mathrm{~mL} 30 \%$ 的高氯酸继续萃取 $120 \mathrm{~min}$, 离心 $10 \mathrm{~min}$ 后收集上清液用于测定淀粉含量. 可溶性糖的测定使用 $1 \mathrm{~g} / \mathrm{L}$ 的葡 萄糖溶液做标准曲线, 用葱酮试剂法测定 ${ }^{[25]}$, 游离氨基酸的测定用 $3 \mathrm{mg} / \mathrm{L}$ 的丙氨酸做标准曲线, 用茚满三 酮一抗坏血酸法测定 ${ }^{[26]}$. 淀粉含量用 $5 \mathrm{~g} / \mathrm{L}$ 的淀粉溶液做标准曲线,用碘试剂法测定 ${ }^{[27]}$.

\section{6 分析方法}

使用 SPSS 22 软件进行统计分析, 双因素方差分析时间和物种两因素对存活率、相对株高、相对生物量 的效应, 并使用 LSD 法对不同物种的组间差异进行事后多重比较, 方差分析前所有数据进行正态分布和方 差齐性检验, 将存活率与时间进行非线性拟合分析, 游离氨基酸、可溶性糖、淀粉、碳和氮含量与时间进行线 性拟合分析, Pearson 相关性分析相对株高、相对生物量、游离氨基酸、可溶性糖、淀粉、碳、氮含量彼此之间的 相关性. 使用 Origin 2017 软件绘图.

\section{2 实验结果}

\section{1 水质}

实验期间, 湖心平台区域水体透明度为 $1.5 \sim 2.0 \mathrm{~m}$, 水深为 $6.1 \sim 6.6 \mathrm{~m}$, 湖底光照强度为 $8.3 \sim 15.8 \mu \mathrm{mol} /$ $\left(\mathrm{m}^{2} \cdot \mathrm{s}\right)$. 水温为 $21.4 \sim 24.6^{\circ} \mathrm{C}, \mathrm{TN}$ 浓度 $0.56 \sim 0.98 \mathrm{mg} / \mathrm{L}, \mathrm{NH}_{3}-\mathrm{N}$ 浓度 $0.012 \sim 0.071 \mathrm{mg} / \mathrm{L}, \mathrm{NO}_{3}^{-}-\mathrm{N}$ 浓度 $0.031 \sim$ $0.052 \mathrm{mg} / \mathrm{L}, \mathrm{TP}$ 浓度 $0.034 \sim 0.048 \mathrm{mg} / \mathrm{L}, \mathrm{PO}_{4}^{3-}-\mathrm{P}$ 浓度 $0.002 \sim 0.015 \mathrm{mg} / \mathrm{L}$, 总体上表现为地表亚类水质(图 2).
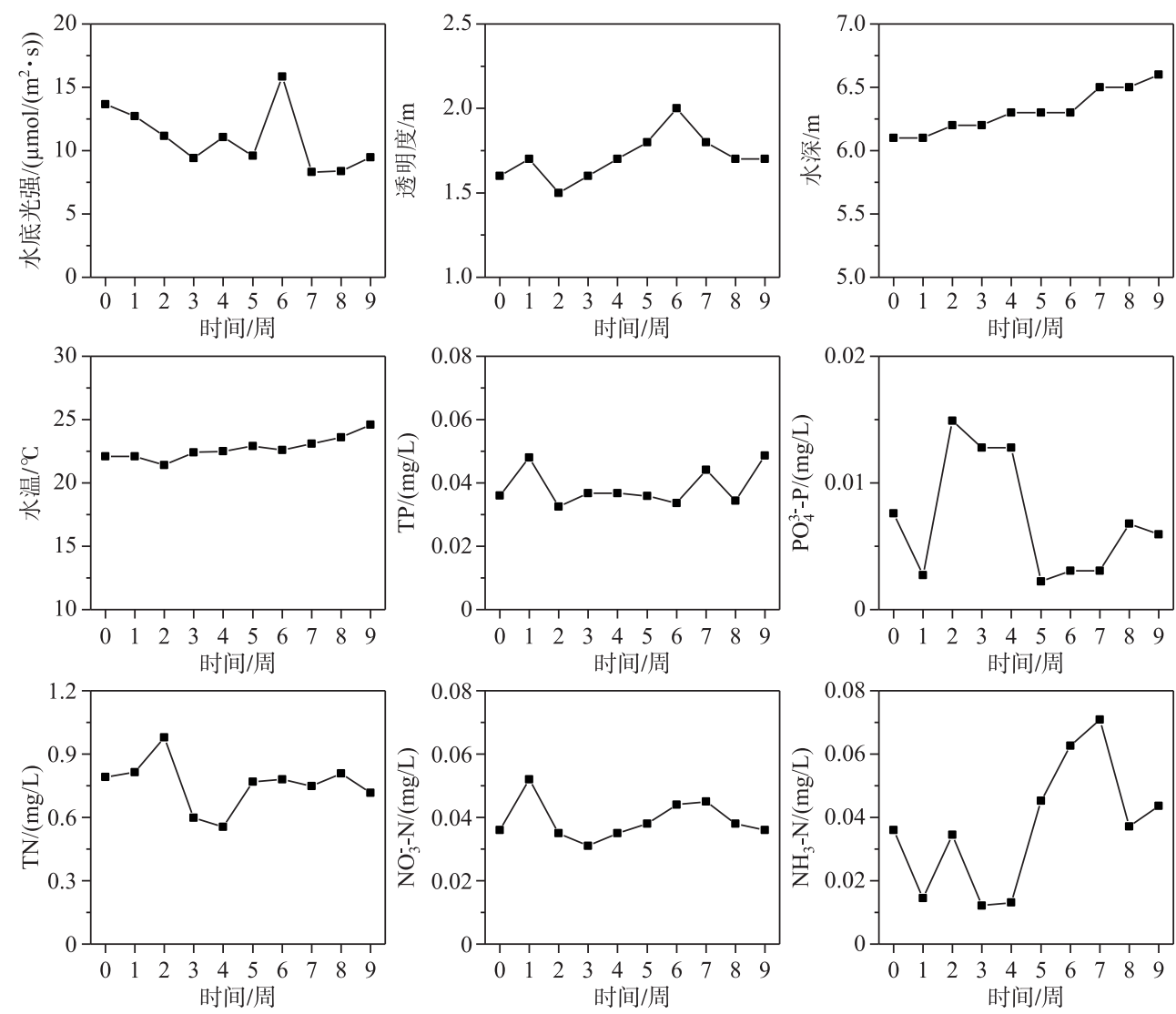

图 2 实验区域的水环境特征

Fig.2 Water environment characteristics in experimental area 


\section{2 形态指标差异}

实验开始后, 4 种沉水植物存活率显著下降, 其中苦草的存活率在第 6 周后逐渐稳定, 实验结束时存活 率为 $35 \%$; 而轮叶黑藻、穗花狐尾藻和竹叶眼子菜的存活率在实验开始后持续下降, 轮叶黑藻的存活率在第 4 周降到 0 ; 穗花狐尾藻的存活率在第 6 周降到 0 ; 竹叶眼子菜的存活率在实验结束时降到 $2 \%$ (图 2). 植物 最终存活率在不同植物间存在显著差异, 植物存活率随时间逐渐显著降低 $(P<0.05)$ ( 表 2), 将 4 种沉水植 物的存活率进行多重比较 (LSD), 4 种水生植物的存活率表现为: 苦草 $>$ 竹叶眼子菜 $>$ 穗花狐尾藻 $>$ 轮叶 黑藻 $(P<0.05)$ ( 图 3).

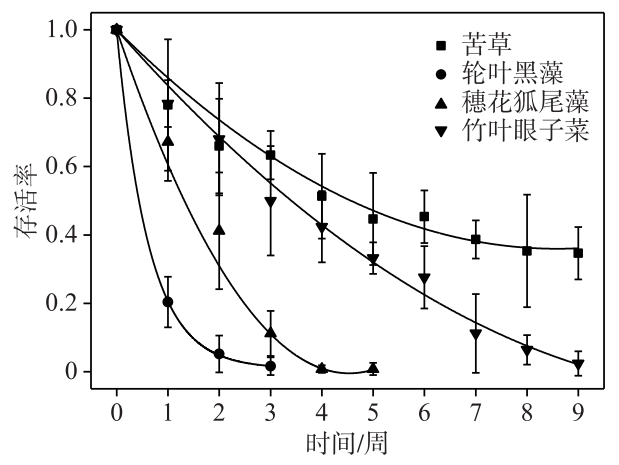

图 34 种沉水植物的存活率变化

Fig.3 Changes in survival rates of four submerged macrophytes

弱光环境下, 4 种沉水植物生长受到抑制, 单株生物量和株高都显著性下降. 实验结束时, 苦草生物量降 低到初始值的 $12.2 \%$; 轮叶黑藻在第 3 周的相对生物量降至初始生物量的 $1.8 \%$, 随后轮叶黑藻全部死亡; 穗 花狐尾藻在第 5 周的相对生物量降至 4.6\%, 随后穗花狐尾藻完全死亡; 竹叶眼子菜的相对生物量在实验结 束时降至 4.3\% (图 4). 双因素方差分析表明, 时间和物种对相对生物量均有显著性影响 (表 2),4种沉水植 物的相对生物量多重比较 (LSD) 表明, 苦草和竹叶眼子菜 > 轮叶黑藻和穗花狐尾藻. 实验期间, 苦草相对株 高降到 64.2\% ; 竹叶眼子菜相对株高从 1 降到 10.9\%; 第 3 周, 轮叶黑藻相对株高降至 7.3\%, 随后轮叶黑藻 全部死亡; 第 5 周, 穗花狐尾藻相对株高降至 4.1\%, 随后完全死亡(图 4). 双因素方差分析表明, 时间和物种 对相对株高的影响都具有显著性, 4 种沉水植物的相对株高进行多重比较 (LSD) 表明, 苦草 > 竹叶眼子菜 > 穗花狐尾藻 > 轮叶黑藻(表 2).
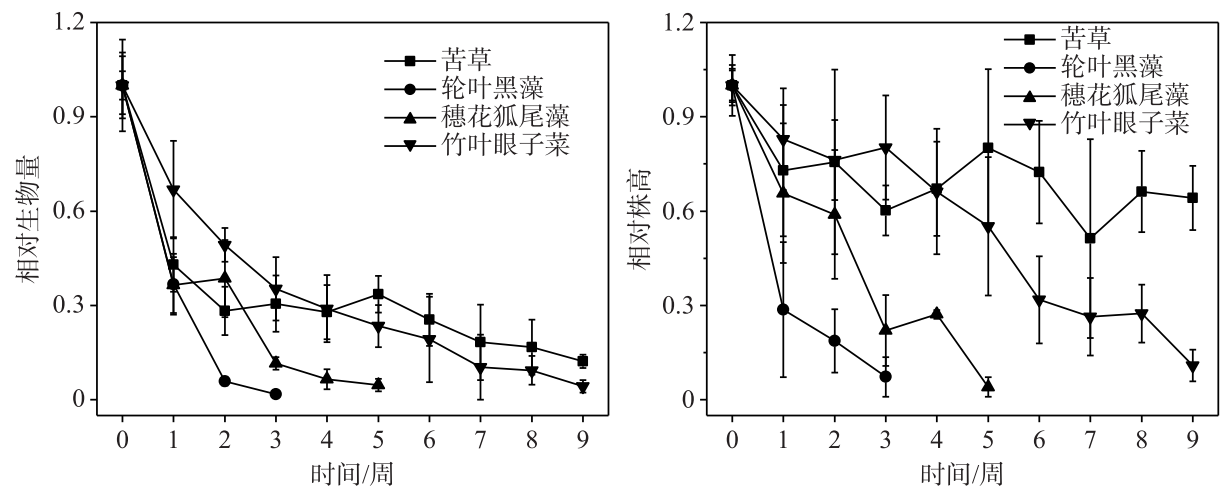

图 44 种沉水植物相对株高和单株生物量变化

Fig.4 Changes of relative plant height and individual biomass of four submerged macrophytes 
表 24 种沉水植物存活率、相对生物量和相对株高双因素方差分析

Tab.2 Two-factor variance analysis of survival rate, relative biomass and relative plant height of four submerged macrophytes

\begin{tabular}{|c|c|c|c|c|}
\hline & \multicolumn{4}{|c|}{ 方差变异百分比/\% } \\
\hline & 时间 & 物种 & 时间×物种 & 误差 \\
\hline 存活率 & $63.4^{* * * *}$ & $22.9^{* * *}$ & $8.2^{* * *}$ & 5.5 \\
\hline 相对生物量 & $81.4^{* * *}$ & $7.6^{* * *}$ & $5.2^{* * *}$ & 5.8 \\
\hline 相对株高 & $40.7^{\text {***** }}$ & $28.1^{* * * *}$ & $15.0^{\text {***** }}$ & 16.2 \\
\hline
\end{tabular}

$* P<0.05, * * P<0.01, * * * P<0.001$.

\section{3 生理指标差异}

弱光环境下, 4 种沉水植物的叶绿素含量变化趋势不同, 苦草叶绿素含量总体呈波动上升趋势, 初始值 和结束值分别为 0.58 和 $1.1 \mathrm{mg} / \mathrm{g}$; 轮叶黑藻叶绿素含量呈下降趋势, 其初始值和结束值分别是 1.14 和 0.30 $\mathrm{mg} / \mathrm{g}$; 穗花狐尾藻和竹叶眼子菜叶绿素含量相对稳定 (图 5 ).
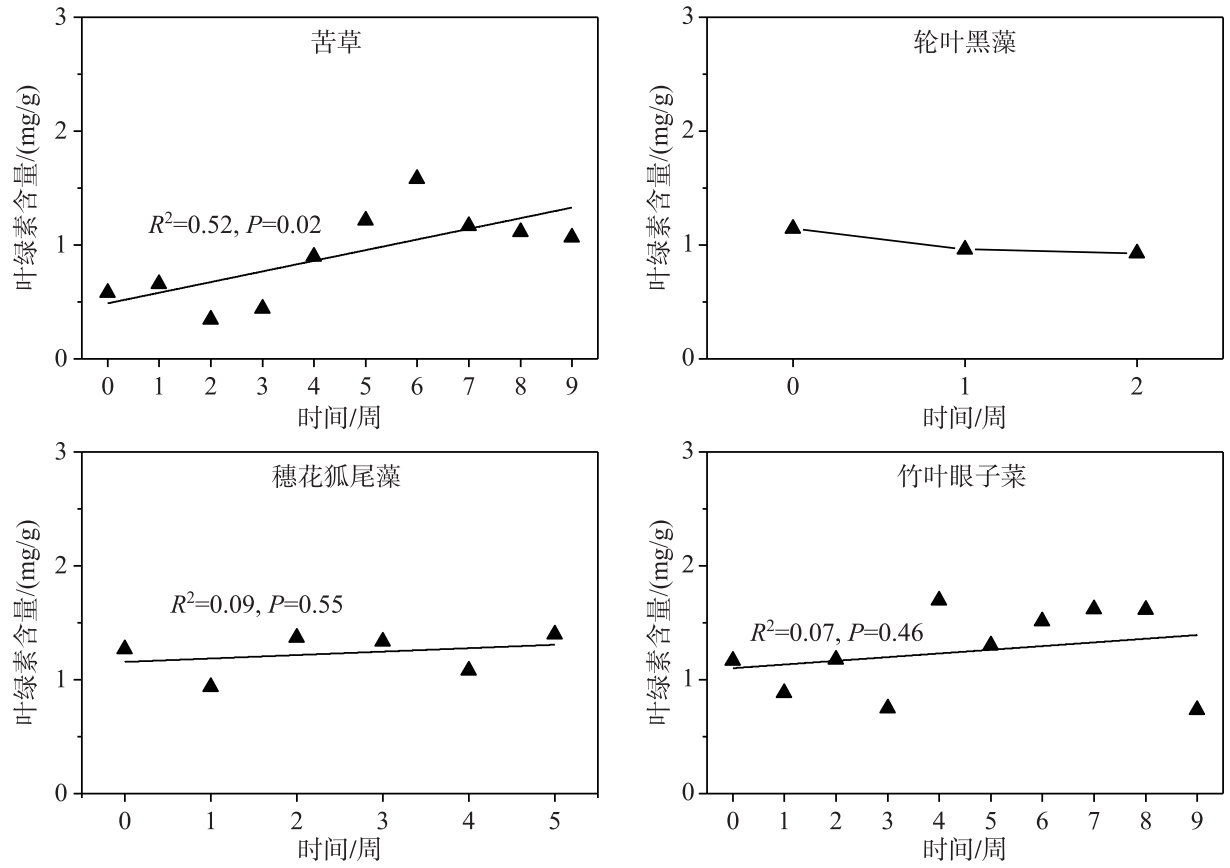

图 54 种沉水植物的叶绿素含量变化

Fig.5 Changes of chlorophyll content of four submerged macrophytes

实验开始后, 苦草、穗花狐尾藻和竹叶眼子菜 $\mathrm{N}$ 含量升高, 其中苦草、穗花狐尾藻和竹叶眼子菜 $\mathrm{N}$ 含量 初始值是 $0.93 \% 、 1.39 \%$ 和 $1.27 \%$, 实验结束时 $\mathrm{N}$ 含量分别上升到 $2.58 \% 、 4.01 \%$ 和 $1.74 \%$; 而轮叶黑藻 $\mathrm{N}$ 含 量初始值是 $3.47 \%$, 实验开始后, 轮叶黑藻 $\mathrm{N}$ 含量变化不明显 (图 6). 苦草 C 含量下降, 由初始时的 $37 \%$ 下 降到实验结束时的 $31 \%$; 轮叶黑藻和穗花狐尾藻 $\mathrm{C}$ 含量升高, 轮叶黑藻和穗花狐尾藻的 $\mathrm{C}$ 含量的初始值分 别为 32\% 和 30\%, 实验结束时分别上升到 36\% 和 $40 \%$; 实验前 5 周, 竹叶眼子菜的 C 含量呈上升趋势, 第 5 周到实验结束时呈下降趋势, 实验开始时、第 5 周和实验结束时的 C 含量分别为 38\%、43\% 和 36\% (图 6). 苦草、穗花狐尾藻和竹叶眼子菜 $\mathrm{C}: \mathrm{N}$ 比降低, 其初始值分别是 $39.6 、 21.9$ 和 30.3 , 结束时, $\mathrm{C}: \mathrm{N}$ 比分别是 12.2、9.9 和 20.7; 轮叶黑藻 $\mathrm{C}: \mathrm{N}$ 比变化不大, 其初始和结束值分别为 9.3 和 10.7(图 6). 

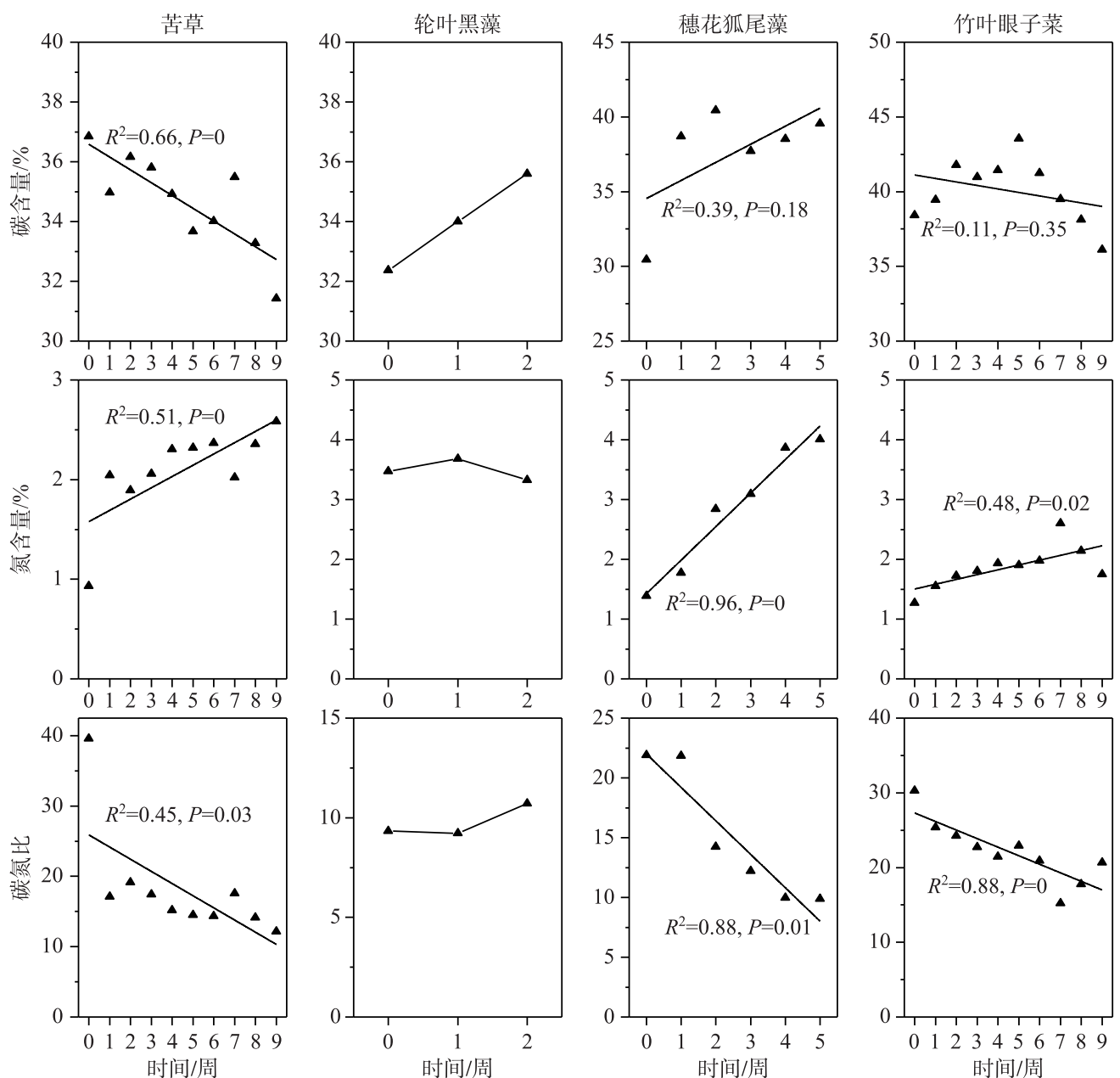

图 64 种沉水植物 $\mathrm{C} 、 \mathrm{~N}$ 含量以及 $\mathrm{C}: \mathrm{N}$ 比变化

Fig.6 Changes of $\mathrm{C}, \mathrm{N}$ contents and $\mathrm{C}: \mathrm{N}$ ratios of four submerged macrophytes

实验期间,苦草、穗花狐尾藻和竹叶眼子菜的游离氨基酸含量随时间呈上升趋势, 初始时, 苦草、穗花狐 尾藻和竹叶眼子菜游离氨基酸含量分别是 $0.25 、 0.84 、 0.49 \mathrm{mg} / \mathrm{g}$, 实验时的最大含量分别达到 $1.05 、 2.02 、 1.1$ $\mathrm{mg} / \mathrm{g}$; 而轮叶黑藻的游离氨基酸含量随时间呈下降趋势, 其氨基酸含量由初始值的 $1.16 \mathrm{mg} / \mathrm{g}$ 下降到 0.61 $\mathrm{mg} / \mathrm{g}$, 并且轮叶黑藻的氨基酸含量与时间呈显著负相关 (图 7). 苦草、穗花狐尾藻和竹叶眼子菜的可溶性糖 含量随时间呈下降趋势, 其可溶性糖含量的初始值分别是 15.37、26.67 和 $32.97 \mathrm{mg} / \mathrm{g}$, 实验结束时可溶性糖 含量分别下降到 8.03、8.53 和 $6.98 \mathrm{mg} / \mathrm{g}$; 而轮叶黑藻的可溶性糖含量随时间呈上升趋势, 其可溶性糖含量由 初始值的 $5.52 \mathrm{mg} / \mathrm{g}$ 上升到 $16.35 \mathrm{mg} / \mathrm{g}$ ( 图 7). 苦草、穗花狐尾藻和竹叶眼子菜的淀粉含量随时间呈下降趋 势, 其淀粉含量的初始值分别是 $257 、 65$ 和 $163 \mathrm{mg} / \mathrm{g}$, 实验结束时淀粉含量分别下降到 $55 、 11$ 和 $12 \mathrm{mg} / \mathrm{g}$; 而 轮叶黑藻的淀粉含量随时间变化呈上升趋势, 其可溶性糖含量由初始值的 $2 \mathrm{mg} / \mathrm{g}$ 上升到 $28 \mathrm{mg} / \mathrm{g}$ (图 7).

苦草株高、单株生物量与游离氨基酸含量均呈显著性负相关, 并且株高、单株生物量与氮含量也都呈显 著性负相关, 而单株生物量与淀粉含量呈显著正相关. 轮叶黑藻两个形态指标株高、单株生物量与 5 个生理 指标都没有表现出显著性相关. 穗花狐尾藻与可溶性糖、淀粉含量呈显著性正相关, 而株高、单株生物量与 氮含量都呈显著性负相关 (表 3). 竹叶眼子菜株高、单株生物量与淀粉含量都呈显著性正相关, 并且株高、 单株生物量与碳含量也都呈显著性正相关,单株生物量与可溶性糖含量呈显著性正相关, 而株高、单株生物 

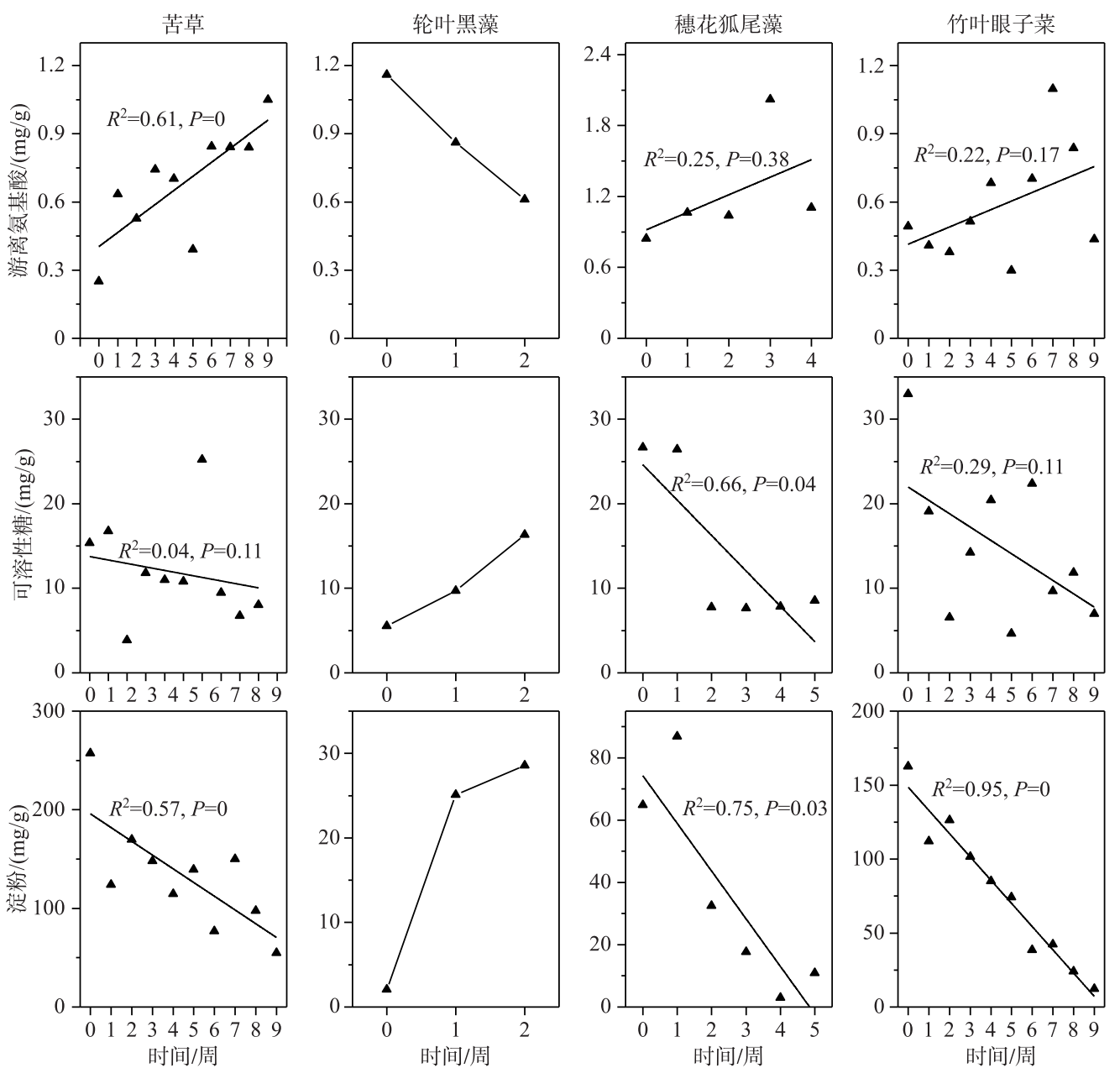

图 74 种沉水植物游离氨基酸、可溶性糖和淀粉含量变化

Fig.7 Changes of free amino acid, soluble carbohydrates and starch content in four submerged macrophytes

量与氮含量都呈显著性负相关 (表 3).

\section{3 分析与讨论}

沉水植物的生长、繁殖受到多种环境因素的影响, 本研究水域水温、水体营养盐都在适合沉水植物生长 的范围 ${ }^{[28-29]}$, 而水下光合有效辐射都远小于相似环境下 4 种沉水植物的光饱和点 ${ }^{[30-31]}$, 所以研究水域的水 下光强最有可能成为影响南部湖心区域沉水植被恢复的主要限制因子. 也有前人研究表明, 洱海透明度下 降对沉水植物造成弱光胁迫, 这是导致洱海沉水植被退化的重要因素 ${ }^{[13]}$.

通过观测沉水植物的存活率、株高和单株生物量的变化, 可以反映出其生长状况和适应能力. 弱光环境 下,四者存活率、株高和单株生物量均显著性下降, 说明湖心区域的弱光条件抑制了沉水植物的生长, 这与 其他研究者报道的结果一致 ${ }^{[32-33]}$. 四者中苦草的最终存活率最高,且其相对生物量和相对株高均高于其他 3 种植物, 说明苦草对湖心平台弱光环境的耐受能力最强.

在弱光环境下, 沉水植物通常会加快光合色素的合成, 增加叶绿素的含量来获取更大的光合作用能 力 $^{[34]}$, 这也体现了沉水植物对弱光的适应, 4 种植物中, 仅苦草的叶绿素含量呈上升趋势, 穗花狐尾藻和竹 叶眼子菜叶绿素含量变化不大, 而轮叶黑藻叶绿素含量下降, 苦草叶片叶绿素含量的升高可以提升对光的 
表 34 种沉水植物生长指标和生理指标的 Pearson 相关性分析

Tab.3 Pearson correlation analysis of growth and physiological indexes of four submerged macrophytes

\begin{tabular}{|c|c|c|c|c|c|c|c|}
\hline 沉水植物 & 指标 & 株高 & 游离氨基酸 & 可溶性糖 & 淀粉 & 碳 & 氮 \\
\hline \multirow[t]{6}{*}{ 苦草 } & 单株生物量 & $0.89^{* *}$ & $-0.83^{* *}$ & 0.45 & $0.72 *$ & 0.52 & $-0.79^{* *}$ \\
\hline & 株高 & & $-0.81^{* *}$ & 0.26 & 0.61 & 0.32 & $-0.67 *$ \\
\hline & 游离氨基酸 & & & -0.06 & $-0.84^{* *}$ & $-0.65^{*}$ & $0.74^{*}$ \\
\hline & 可溶性糖 & & & & -0.07 & 0.08 & -0.10 \\
\hline & 淀粉 & & & & & $0.85^{* *}$ & $-0.95^{* * *}$ \\
\hline & 碳 & & & & & & $-0.80^{* *}$ \\
\hline \multirow[t]{6}{*}{ 轮叶黑藻 } & 单株生物量 & 0.79 & - & -0.97 & -0.96 & -0.99 & 0.28 \\
\hline & 株高 & & 0.74 & -0.61 & -0.93 & -0.71 & -0.36 \\
\hline & 游离氨基酸 & & & -0.98 & -0.94 & $-1.00^{*}$ & 0.36 \\
\hline & 可溶性糖 & & & & 0.86 & 0.99 & -0.52 \\
\hline & 淀粉 & & & & & 0.92 & -0.01 \\
\hline & 碳 & & & & & & -0.40 \\
\hline \multirow[t]{6}{*}{ 穗花狐尾藻 } & 单株生物量 & $0.98^{*}$ & -0.55 & 0.75 & 0.71 & -0.78 & $-0.89^{*}$ \\
\hline & 株高 & & -0.59 & 0.80 & 0.79 & -0.69 & $-0.92^{* *}$ \\
\hline & 游离氨基酸 & & & -0.50 & -0.43 & 0.27 & 0.36 \\
\hline & 可溶性糖 & & & & $0.93^{* *}$ & -0.64 & $-0.89^{*}$ \\
\hline & 淀粉 & & & & & -0.41 & $-0.93^{* *}$ \\
\hline & 碳 & & & & & & 0.65 \\
\hline \multirow[t]{6}{*}{ 竹叶眼子菜 } & 单株生物量 & $0.88^{* *}$ & -0.43 & $0.66^{*}$ & $0.95^{* * * *}$ & $0.90^{* * * *}$ & $-0.77^{* *}$ \\
\hline & 株高 & & -0.50 & 0.44 & $0.95^{* * * *}$ & $0.79^{* *}$ & $-0.65^{*}$ \\
\hline & 游离氨基酸 & & & 0.08 & -0.47 & $-0.73^{*}$ & $0.79^{* * *}$ \\
\hline & 可溶性糖 & & & & 0.49 & 0.56 & -0.49 \\
\hline & 淀粉 & & & & & $0.85^{* *}$ & $-0.69^{*}$ \\
\hline & 碳 & & & & & & $-0.95^{* * * *}$ \\
\hline
\end{tabular}

表中数据为相关系数; “一”表示数据太少, 不进行分析, * : $P<0.05, * *: P<0.01, * * *: P<0.001$.

获取能力,一定程度上反映了苦草对弱光环境具有相对较强的适应能力.

通常在弱光环境下植株具有较低的可溶性糖和淀粉含量以及 $\mathrm{C}: \mathrm{N}$ 比, 而具有更高的游离氨基酸和氮含 量 ${ }^{[35-36]}$, 因此检测沉水植物的氮、碳含量和代谢物含量, 有利于反映植物受胁迫的程度. $\mathrm{N}$ 是蛋白质的重要 组成元素, C 是植物的结构性元素, 对植物生长有重要的影响 ${ }^{[37-38]}$, 并且生物在变化的环境中具有保持自身 化学组成相对稳定的能力 ${ }^{[39]}$, 所以研究逆境条件下沉水植物的 $C 、 N$ 变化具有重要意义. 弱光环境下, 苦草、 穗花狐尾藻和竹叶眼子菜的 $\mathrm{N}$ 含量均升高, $\mathrm{C}: \mathrm{N}$ 比均下降, 反映了这 3 种沉水植物在生理上的胁迫响应, 实 验结果与前人研究一致 ${ }^{[35]}$, 而这 3 种沉水植物的 $\mathrm{C}$ 含量表现出差异性, 穗花狐尾藻 $\mathrm{C}$ 含量升高, 竹叶眼子菜 在实验前期也有上升的趋势, 这或许与二者大量叶片腐烂掉落使茎的生物量占比升高有关, 因为沉水植物 茎的 C 含量比例相对较高 ${ }^{[40]}$. 轮叶黑藻 $\mathrm{C} 、 \mathrm{~N}$ 含量变化与其他 3 种沉水植物不同, 轮叶黑藻 $\mathrm{C}$ 含量上升, 而 $\mathrm{N}$ 含量和 $\mathrm{C}: \mathrm{N}$ 比变化不明显.

氨基酸是合成生物体内酶的物质基础, 是指示环境胁迫的重要生理指标 ${ }^{[41-42]}$. 可溶性糖是植物能直接 利用的能源物质 ${ }^{[43]}$, 在弱光胁迫下, 光合作用合成糖类的量都很低, 植株需要消耗淀粉转化可溶性糖以提供 能量基础,所以植株储存的碳水化合物的含量与植物对不良环境的耐受能力息息相关 ${ }^{[44]}$. 弱光环境下,4 种 沉水植物有不同的生理响应, 苦草、穗花狐尾藻和竹叶眼子菜的代谢物含量变化的趋势一致(氨基酸含量升 高, 可溶性糖和淀粉含量下降), 3 种沉水植物都在生理特征上表现出胁迫响应,但是仅有苦草的氨基酸含量 呈现持续上升的趋势, 并且在实验期间, 苦草淀粉含量一直保持在较高的水平, 而穗花狐尾藻和竹叶眼子菜 淀粉含量持续下降至极低值, 这也一定程度反映了苦草对弱光环境具有相对较强的耐受能力. 轮叶黑藻 3 
种代谢物含量的变化与其他 3 种沉水植物完全相反,可溶性糖和淀粉含量上升,氨基酸含量下降. 就轮叶黑 藻生理响应异与其他 3 种沉水植物的问题, 推测出一个可能性, 轮叶黑藻在弱光胁迫下有相异于其他植物 的适应方式,随着轮叶黑藻生物量和株高的下降,轮叶黑藻部分营养成分逐渐流向胁迫损伤较小的部位.

从 4 种沉水植物生理与生长指标之间的 Pearson 相关性分析来看, 苦草、穗花狐尾藻和竹叶眼子菜的 $\mathrm{N}$ 含量与株高和生物量的相关性都有显著性, 苦草和竹叶眼子菜的淀粉含量与生物量显著性相关, 说明这 3 种沉水植物生长指标的下降与生理上的胁迫响应相关, 其中 $\mathrm{N}$ 含量与生长指标的相关性最强, 淀粉含量其 次. 而轮叶黑藻的生理指标与形态指标之间均没有显著性差异, 或许是数据不足的原因, 也可能是因为黑藻 具有异于其他三者的适应弱光的方式.

当前, 国内已有不少尝试恢复水生植被的案例, 比如在太湖、洪湖、白洋淀、杭州西湖和武汉东湖等均有 实践, 弱光限制是水生植被恢复中经常遇到的问题, 前辈们对此提出了不少恢复策略, 比如降低水位、改善 水质条件、提高透明度、选择耐弱光的物种、选择适宜的种植季节等 ${ }^{[45-49]}$. 在水生植物物种选择和群落配置 问题上, 可以根据当地具体自然条件因地制宜、因时制宜, 优先考虑选择少量先锋物种, 先恢复生态系统的 基本结构和功能, 随着生境条件的不断改善, 逐步引人新的物种, 增加物种的多样性 ${ }^{[50]}$, 本次实验发现, 4 种 沉水植物中, 苦草对湖心平台弱光环境的适应能力最强, 可以考虑将苦草作为沉水植被恢复的先锋物种, 待 生境条件进一步改善后, 引人其他沉水植物, 加强植被群落结构的合理性. 虽然本实验比较了洱海 4 种沉水 植物的弱光适应能力, 但是从适应能力最强的苦草的生长特征来看, 苦草存活数量、生物量和株高下降, 并 且没有大量分株, 持续的弱光环境也会进一步降低苦草的耐受能力, 若要实现湖心平台沉水植被的恢复, 还 需要进一步改善湖心平台的环境条件,同时提高人工恢复的种群密度,利用集群效应提高其存活率.

\section{4 结论}

湖心平台水下的弱光环境抑制了 4 种沉水植物的生长, 并表现出不同程度的胁迫反应. 4 种沉水植物的 株高和生物量均显著性降低; 在生理特征上, 苦草、穗花狐尾藻和竹叶眼子菜均有相似的生理胁迫反应, 表 现为: $\mathrm{N}$ 含量升高, 游离氨基酸含量升高, $\mathrm{C}: \mathrm{N}$ 比、可溶性糖和淀粉含量下降, 但是仅有苦草的叶绿素含量升 高,黑藻有异于其他 3 种植物的胁迫反应,其氨基酸含量下降,可溶性糖和淀粉含量升高.

比较 4 种沉水植物的存活率, 表现为苦草 > 竹叶眼子菜 > 穗花狐尾藻 > 轮叶黑藻, 并且苦草相对生物 量和相对株高均高于其他 3 种沉水植物, 说明苦草更能适应湖心平台区域的弱光环境, 可考虑作为湖心平 台水生植被恢复的目标物种. 从苦草的存活量、生物量持续下降的情况来分析,若要实现湖心平台水生植被 的恢复,仍需要进一步改善环境条件.

本实验初步尝试在洱海的水生植被重度退化区 (湖心平台) 进行植被恢复, 从 4 个本地种中比较篮选出 适应能力最强的苦草, 并每隔 1 周采样分析其生长和生理状况, 为湖心平台水生植被的恢复策略提供基础 数据和参考.

致谢: 感谢姚轶倩硕士在实验采样过程中的帮助, 感谢文紫豪和任文静博士在数据分析过程中的帮助.

\section{5 参考文献}

[ 1 ] Xu QJ, Jin XC, Yan CZ. Macrophyte degradation status and countermeasures in China. Ecology and Environment, 2006, 15(5) : 1126-1130. [许秋瑾, 金相灿, 颜昌宙. 中国湖泊水生植被退化现状与对策. 生态环境, 2006, 15(5): 1126-1130.]

[ 2 ] Carpenter SR, Ludwig D, Brock WA. Management of eutrophication for lakes subject to potentially irreversible change. Ecological Applications, 1999, 9(3) : 751-771.

[ 3 ] Carpenter SR, Lodge DM. Effects of submersed macrophytes on ecosystem processes. Aquatic Botany, 1986, 26: 341-370. DOI: $10.1016 / 0304-3770$ ( 86) 90031-8.

[ 4 ] Sand-Jensen K, Borum J. Interactions among phytoplankton, periphyton, and macrophytes in temperate freshwaters and estuaries. Aquatic Botany, 1991, 41(1/2/3) : 137-175. DOI: 10.1016/0304-3770(91)90042-4.

[ 5 ] Guo YQ, Xue JH, Wu YB et al. Research progress on purification effects and restoration technologies of submerged macrophytes on eutrophic water. Journal of Plant Resources and Environment, 2020, 29(3): 58-68. [郭雅倩, 薛建辉, 吴永 
波等. 沉水植物对富营养化水体的净化作用及修复技术研究进展. 植物资源与环境学报, 2020, 29(3): 58-68.]

[ 6 ] Naiman RJ, Magnuson JJ, McKnight DM et al. Freshwater ecosystems and their management: A national initiative. Science, 1995, 270(5236) : 584-585. DOI: 10.1126/science.270.5236.584.

[ 7 ] Qiu DR, Wu ZB, Liu BY et al. The restoration of aquatic macrophytes for improving water quality in a hypertrophic shallow lake in Hubei Province, China. Ecological Engineering, 2001, 18(2) : 147-156. DOI: 10.1016/S0925-8574( 01 ) 00074-X.

[ 8 ] Rosińska J, Rybak M, Gołdyn R. Patterns of macrophyte community recovery as a result of the restoration of a shallow urban lake. Aquatic Botany, 2017, 138: 45-52. DOI: 10.1016/j.aquabot.2016.12.005.

[ 9 ] Zheng ZM, Song GY, Zhou ZX et al. Classified conservation and restoration of vegetation in Wuhan urban lake wetlands based on plant diversity characteristics. Acta Ecologica Sinica, 2010, 30(24) : 7045-7054. [郑忠明, 宋广芗, 周志翔 等. 基于植物多样性特征的武汉市城市湖泊湿地植被分类保护和恢复. 生态学报, 2010, 30(24) : 7045-7054.]

[10] Qin BQ. Principles and approach for lake ecological restoration. Acta Ecologica Sinica , 2007, 27(11) : 4848-4858. [秦伯 强. 湖泊生态恢复的基本原理与实现. 生态学报, 2007, 27(11): 4848-4858.]

[11] Wang H, Pang Y, Liu SB et al. Research progress on influencing of environmental factors on the growth of submersed macrophytes. Acta Ecologica Sinica, 2008, 28(8): 3958-3968. [王华, 逢勇, 刘申宝等. 沉水植物生长影响因子研究进 展. 生态学报, 2008, 28(8) : 3958-3968.]

[12] Wang SH, Zhao DF, Liao RH. Research on water body illuminance and compensation depth of submergedmacrophyte in lake. Technology of Water Treatment, 2006, 32(6): 31-33. [王韶华, 赵德锋, 廖日红. 关于北京后海水体光照强度 及沉水植物光补偿深度的研究. 水处理技术, 2006, 32(6): 31-33.]

[13] Fu H, Yuan GX, Cao T et al. Succession of submerged macrophyte communities in relation to environmental change in Lake Erhai over the past 50 years. J Lake Sci, 2013, 25(6): 854-861. DOI: 10.18307/2013.0609. [符辉, 袁桂香, 曹 特等. 洱海近 50a 来沉水植被演替及其主要驱动要素. 湖泊科学, 2013, 25(6): 854-861.]

[14] Zhan JC, Huang WD, Wang LJ. Research of weak light stress physiology in plants. Chinese Bulletin of Botany, 2003, 20 (1) : 43-50. [ 战吉宬, 黄卫东, 王利军. 植物弱光逆境生理研究综述. 植物学通报, 2003, 20(1) : 43-50.]

[15] Chen J, Cao T, Zhang XL et al. Differential photosynthetic and morphological adaptations to low light affect depth distribution of two submersed macrophytes in lakes. Scientific Reports, 6(1): 34028. DOI: 10.1038/srep34028.

[16] Xue WN, Peng YB, Song XF, et al. Effects of light intensity on physiological and biochemical characteristics of Hydrilla verticillata (1.f.) royle. Journal of Anhui Agricultural Sciences, 2012, 40(7) : 4169-4172. [薛维纳, 彭岩波, 宋祥甫等. 弱光胁迫对黑藻生理生化特性的影响. 安徽农业科学, 2012, 40(7) : 4169-4172.]

[17] Dai QY. A preliminary study of the aquatic vegetation in Erhai Lake. Transactions of Oceanology and Limnology, 1984, (4) : 31-41. [戴全裕. 洱海水生植被的初步研究. 海洋湖沼通报, 1984, (4) : 31-41.]

[18] Hu XZ, Jin XC, Du BH et al. Submerged macrophyte of lake Erhai and its dynamic change. Research of Environmental Sciences, 2005, 18(1) : 1-4, 84. DOI: 10.13198/j.res.2005.01.2.huxzh.001. [胡小贞, 金相灿, 杜宝汉等. 云南洱海沉 水植被现状及其动态变化. 环境科学研究, 2005, 18(1): 1-4, 84.]

[19] Dong YX, Xie JP, Dong YS et al. Water vegetation resourees of Lake Erhai and its sustainable utilization ways. Ecological Economy, 1996, 12(5): 15-19. [ 董云仙, 谢建平, 董云生等. 洱海水生植被资源及其可持续利用途径. 生态经济, $1996,12(5): 15-19$.

[20] Li H, Shang YM. Aquatic vegetation in lakeErhai, Yunnan. Journal of Mountain Research, 1989, 7(3): 166-174. [李 恒, 尚榆民. 云南洱海水生植被. 山地研究, 1989, 7(3): 166-174.]

[21] Chu ZS, Ye BB, Tian GP et al. Spatial distribution characteristics and estimation of submerged plant biomass in lake Erhai. Research of Environmental Sciences, 2014, 27(1): 1-5. [储昭升, 叶碧碧, 田桂平等. 洱海沉水植物空间分布及 生物量估算. 环境科学研究, 2014, 27 (1): 1-5.]

[22] Wu ZB ed. Aquatic plants and water ecological restoration. Beijing: Science Press, 2011: 284-286. [吴振斌. 水生植物 与水体生态修复, 北京: 科学出版社, 2011: 284-286. ]

[23] Huang XF, Chen WM, Cai QM eds. Observation and analysis of lake ecology. Beijing: Standards Press of China, 2000. [黄祥飞, 陈伟民, 蔡启铭. 湖泊生态调查观测与分析. 北京:中国标准出版社, 2000.]

[24] Yang MW. Study on rapid determination of chlorophyll content of leaves. Chinese Journal of Spectroscopy Laboratory, 2002, 19(4) : 478-481. [杨敏文. 快速测定植物叶片叶绿素含量方法的探讨. 光谱实验室, 2002, 19(4) : 478-481.] 
[25] Yemm EW, Willis AJ. The estimation of carbohydrates in plant extracts by anthrone. The Biochemical Journal, 1954,57 (3) : 508-514. DOI: 10.1042/bj0570508.

[26] Yemm EW, Cocking EC, Ricketts RE. The determination of amino-acids with ninhydrin. The Analyst, 1955, 80(948): 209. DOI: $10.1039 /$ an9558000209.

[27] Dirk LMA, van der Krol AR, Vreugdenhil D et al. Galactomannan, soluble sugar and starch mobilization following germination of Trigonella foenum-graecum seeds. Plant Physiology and Biochemistry, 1999, 37 (1) : 41-50. DOI: 10.1016/ S0981-9428 ( 99 ) 80065-5.

[28] Santamaría L, van Vierssen W. Photosynthetic temperature responses of fresh- and brackish-water macrophytes: A review. Aquatic Botany, 1997, 58(2) : 135-150. DOI: 10.1016/S0304-3770(97) 00015-6.

[29] Beklioglu M, Moss B. Existence of a macrophyte-dominated clear water state over a very wide range of nutrient concentrations in a small shallow lake. Hydrobiologia, 1996, 337 (1/2/3) : 93-106. DOI: 10.1007/BF00028510.

[30] Su WH, Zhang GF, Zhang YS et al. The photosynthetic characteristics of five submerged aquatic plants. Acta Hydrobiologica Sinica, 2004, 28(4) : 391-395. [苏文华, 张光飞, 张云孙等. 5 种沉水植物的光合特征. 水生生物学报, 2004, 28(4) : 391-395.]

[31] Pilon J, Santamaría L. Clonal variation in morphological and physiological responses to irradiance and photoperiod for the aquatic angiosperm Potamogeton pectinatus. Journal of Ecology, 2002, 90 ( 5 ) : 859-870. DOI: 10.1046/j.1365-2745. 2002.00716.x.

[32] Fu H, Yuan GX, Cao T et al. Clonal growth and foraging behavior of a submerged macrophyte Vallisneria natans in response to water depth gradient. J Lake Sci, 2012, 24(5) : 705-711. DOI: 10.18307/2012.0510. [符辉, 袁桂香, 曹特 等. 水深梯度对苦草 (Vallisneria natans) 克隆生长与受食行为的影响. 湖泊科学, 2012, 24(5) : 705-711.]

[33] Li W, Cao T, Ni LY et al. Size-dependent C, N and P stoichiometry of three submersed macrophytes along water depth gradients. Environmental Earth Sciences, 2015, 74(5) : 3733-3738. DOI: 10.1007/s12665-015-4295-9.

[34] Tavechio WLG, Thomaz SM. Effects of light on the growth and photosynthesis of Egeria najas planchon. Brazilian Archives of Biology and Technology, 2003, 46(2) : 203-209. DOI: 10.1590/s1516-89132003000200011.

[35] Cronin G, Lodge DM. Effects of light and nutrient availability on the growth, allocation, carbon/nitrogen balance, phenolic chemistry, and resistance to herbivory of two freshwater macrophytes. Oecologia, 2003, 137(1): 32-41. DOI: 10. 1007/s00442-003-1315-3.

[36] Zhang M, Cao T, Ni LY et al. Carbon, nitrogen and antioxidant enzyme responses of Potamogeton crispus to both low light and high nutrient stresses. Environmental and Experimental Botany, 2010, 68(1): 44-50. DOI: 10.1016/j. envexpbot. 2009.09.003.

[37] Schulze E, Kelliher FM, Korner C et al. Relationships among maximum stomatal conductance, ecosystem surface conductance, carbon assimilation rate, and plant nitrogen nutrition: A global ecology scaling exercise. Annual Review of Ecology and Systematics, 1994, 25(1) : 629-662. DOI: 10.1146/annurev.es.25.110194.003213.

[38 ] Reich PB, Oleksyn J, Wright IJ. Leaf phosphorus influences the photosynthesis-nitrogen relation: A cross-biome analysis of 314 species. Oecologia, 2009, 160(2) : 207-212. DOI: 10.1007/s00442-009-1291-3.

[39] Sterner RW, Elser JJ eds. Ecological stoichiometry: The biology of elements from molecules to the biosphere. Princeton: Princeton University Press, 2002.

[40] Li W, Cao T, Ni LY et al. Effects of water depth on carbon, nitrogen and phosphorus stoichiometry of five submersed macrophytes in an in situ experiment. Ecological Engineering, 2013, 61: 358-365. DOI: 10.1016/j.ecoleng.2013.09.028.

[41] Cao T, Xie P, Ni LY et al. The role of $\mathrm{NH}_{4}^{+}$toxicity in the decline of the submeerged macrophyte Vallisneria natans in lakes of the Yangtze River. Marine and Freshwater Research, 2007, 58(6) : 581-587.

[42] Zou LS, Nie ZY, Yao XY et al. Effects of light on submerged macrophytes in eutrophic water: Research progress. Chinese Journal of Applied Ecology, 2013, 24(7) : 2073-2080. DOI: 10.13287/j.1001-9332.2013.0407. [邹丽莎, 聂泽宇, 姚 笑颜等. 富营养化水体中光照对沉水植物的影响研究进展. 应用生态学报, 2013, 24(7) : 2073-2080.]

[43] Lambers H. The physiological significance of cyanide-resistant respiration in higher plants. Plant, Cell \& Environment, 1980, 3(5) : 293-302. DOI: 10.1111/1365-3040.ep11581846.

[44] Myers JA, Kitajima K. Carbohydrate storage enhances seedling shade and stress tolerance in a neotropical forest. Journal of Ecology, 2007, 95(2) : 383-395. DOI: 10.1111/j.1365-2745.2006.01207.x. 
[45] Pan G, Yang B, Wang D et al. In-lake algal bloom removal and submerged vegetation restoration using modified local soils. Ecological Engineering, 2011, 37(2) : 302-308. DOI: 10.1016/j.ecoleng.2010.11.019.

[46] Chen HD. An approach to the restoration of aquatic vegetation in the Xihu lake of Hangzhou, with reference to the water quality problem. Acta Hydrobiologica Sinica, 1984, 8(2) : 237-244. [陈洪达. 杭州西湖水生植被恢复的途径与水质 净化问题. 水生生物学集刊, 1984, 8(2): 237-244.]

[47] Qiu DR, Wu ZB, Liu BY et al. Ecological restoration of aquatic vegetation in a eutrophic shallow lake, Donghu lake, Wuhan. J Lake Sci, 1997, 9(2) : 168-174. DOI: 10.18307/1997.0212. [邱东茹, 吴振斌, 刘保元等. 武汉东湖水生植 被的恢复试验研究. 湖泊科学, 1997, 9(2): 168-174.]

[48] Ding XQ, Jia YT, Yang JY et al. Seed bank in aquaculture area of Honghu lake and the strategy of aquatic vegetation restoration. Journal of Central China Normal University: Natural Sciences, 2010, 44(2): 296-300. [丁小青, 贾延亭, 杨娇 艳等. 洪湖养殖区水生植物种子库现状及水生植被恢复策略研究. 华中师范大学学报: 自然科学版, 2010,44 (2) : 296-300.]

[49] Yan J, Wang Y, Wang YB et al. Remediation technology of submerged plants in Baiyangdian Lake based on light compensation depth. Chinese Journal of Environmental Engineering, 2020, 14(10): 2853-2865. [严俊, 王颖, 王一博等. 基于 光补偿深度的白洋淀沉水植物修复技术. 环境工程学报, 2020, 14(10): 2853-2865. ]

[50] Li YJ, Xu QJ, Jin XC et al. Analyses on species selection and community collocation of macrophyte in lake restoration. Techniques and Equipment for Environmental Pollution Control, 2004, 5( 8):23-26. [李英杰, 许秋瑾, 金相灿等. 湖泊 水生植被恢复物种选择及群落配置分析. 环境污染治理技术与设备, 2004, 5(8) : 23-26.] 